\title{
Ideen für eine Insektenbehausung und eine Spatzenvilla
}

\section{Dominik Heukemes}

\section{Zwei kreative Ideen}

In diesem Sommer wollte ich ein Insektenhotel für meinen Garten bauen. Dies habe ich dann auch schnell umgesetzt mit einer alten Apfelkiste, ein paar alten Biberschwanz-Dachziegeln, Buchen-Holzscheiten und Bambusstäben. Bald war alles Material zusammengetragen und die Löcher (Durchmesser $2 \mathrm{~mm}, 4 \mathrm{~mm}, 6 \mathrm{~mm}$ ) waren schnell in die Buchenholz-Scheite gebohrt. Die Kiste wurde dann gen Süden an den Pfosten meiner Spalierquitten-Bäume angebracht. Mit den Ziegeln und Dachlatten war das Dach in kurzer Zeit fertiggestellt.

Leider hat die Kiste das Gewicht nicht lange ausgehalten, darum musste eine neue Idee her, da schon die ersten Gäste eingezogen waren. Bei meinen Eltern im Keller fand ich dann zwei Nachttische meiner Urgroßeltern.

Den einen habe ich zum Insektenhotel umgebaut, aus dem anderen habe ich eine Spatzenvilla für vier Familien gebaut. Leider war am Ende des Sommers die Brutsaison der Spatzen bereits vorüber, so dass diese wahrscheinlich erst im nächsten Jahr einziehen werden.

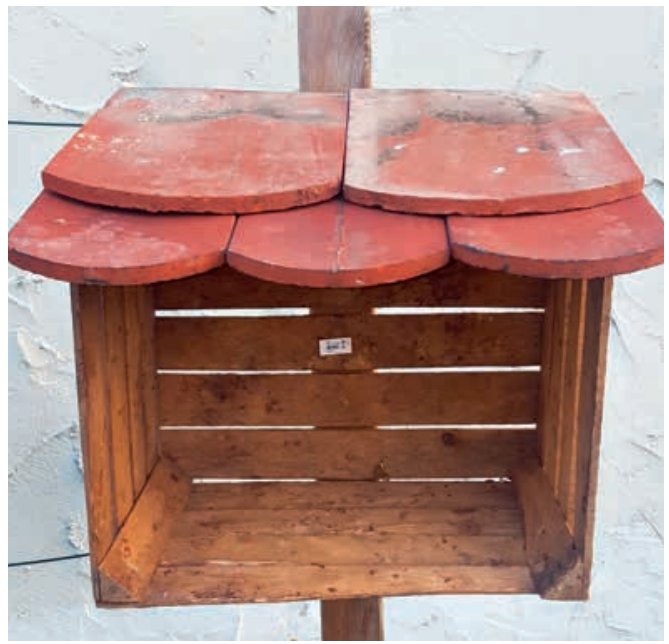

Abb. 1: Eine Apfelkiste als Grundstock für ein Insektenhotel. (Foto: D. Heukemes)

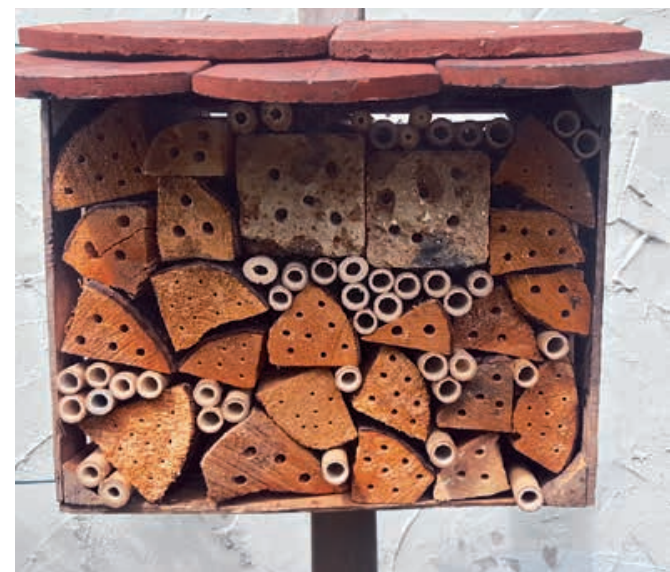

Abb. 2: Das fertige Insektenhotel mit vielen Brutmöglichkeiten. (Foto: D. Heukemes)

\section{Tipps für den Bau von sogenannten Insektenhotels}

Im Zuge der Berichterstattung über das Insektensterben ist es seit einigen Jahren sehr populär geworden, selbst gebaute oder käuflich erworbene Insektenhotels im eigenen Garten, auf Balkon oder Terrasse aufzustellen. Das Angebot käuflicher Modelle ist sehr groß, doch häufig entsprechen sie

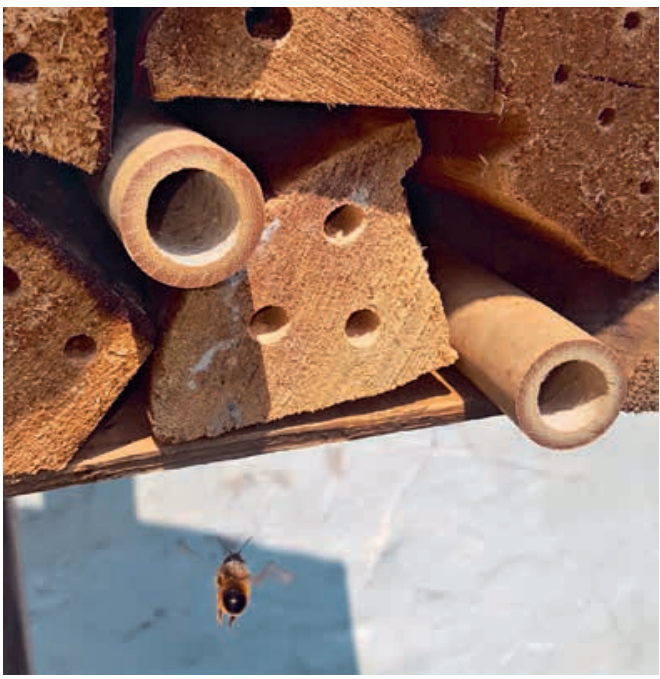

Abb. 3: Das Insektenhotel wird bezogen. (Foto: D. Heukemes) 


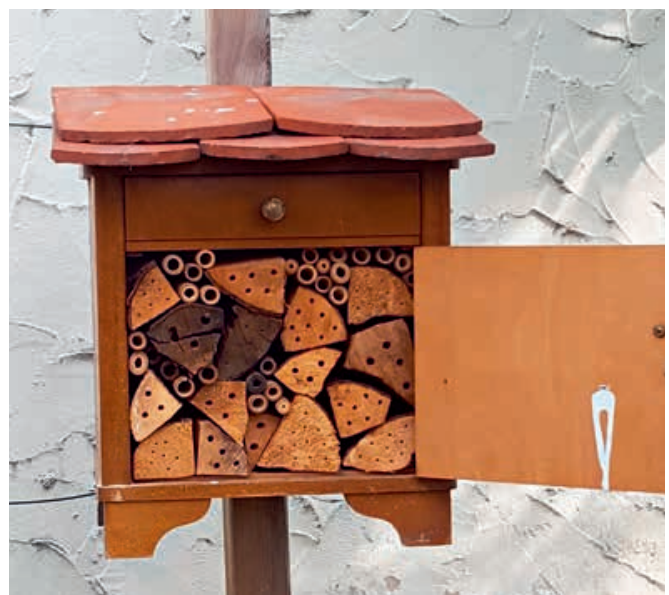

Abb. 4: Die stabilere Variante eines Insektenhotels aus Uromas Nachttisch. (Foto: D. Heukemes)

nicht den Bedürfnissen von Wildbienen. So sollten z. B. Stroh, Heu und Koniferenzapfen vermieden werden. Weichhölzer wie Fichten- oder Kiefernholz sind ungeeignet, da die Insektenflügel durch faserndes Holz oder Harz verletzt werden könnten. Auch Eichenholz ist ungeeignet, da der hohe Gerbstoffgehalt die Brut schädigen könnte. Herkömmliche Lochsteine aus dem Baumarkt werden nicht direkt angenommen, die Löcher müssen mit Schilf- bzw. Bambushalmen oder Pappröhren gefüllt werden. Der Standort sollte sonnig warm und trocken sein.

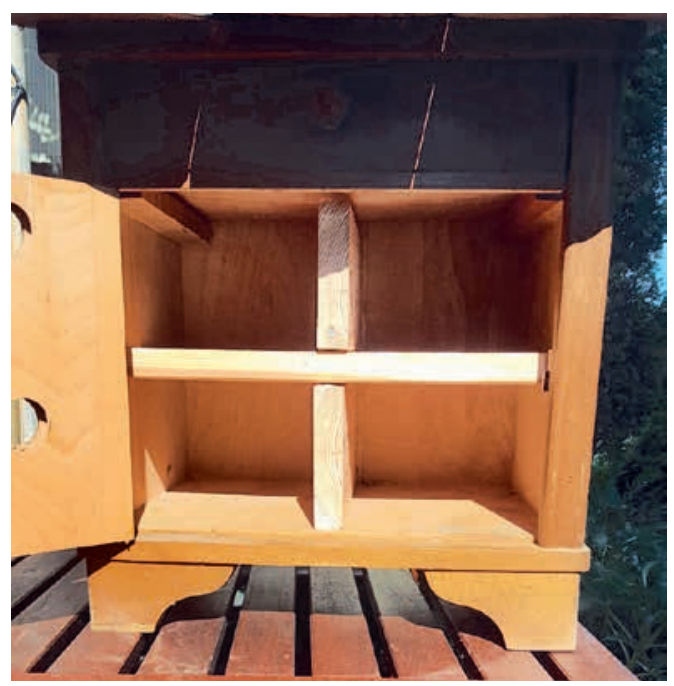

Abb. 6: Platz für vier Spatzenfamilien. (Foto: D. Heukemes)

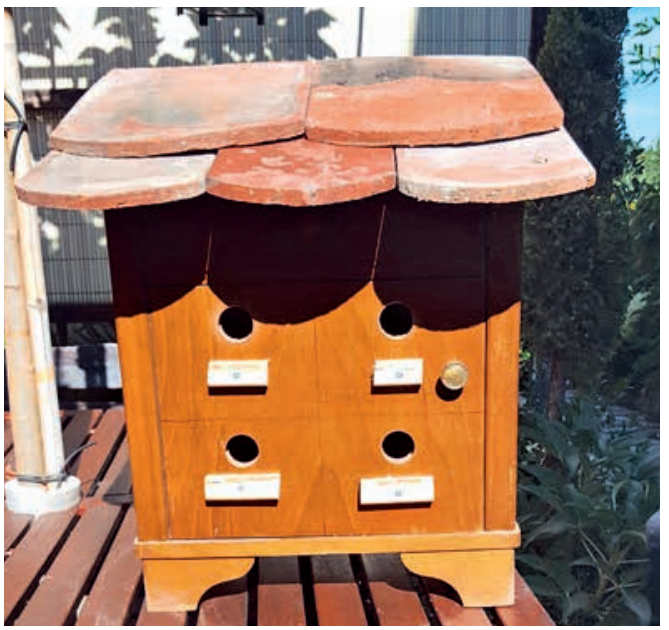

Abb. 5: Die Spatzenvilla ist fertig. (Foto: D. Heukemes)

Ausführliche Tipps für ideale Insekten-Nisthilfen liefert die Broschüre von MAnfred RADTKE „Gefährdete Wildbienen, Nisthilfen bauen und Lebensräume schaffen", heraugegeben vom BUND KG Rotenburg (http://rotenbrug.bund. net).

\section{Anschrift des Autors}

Dominik Heukemes, Palmengarten Frankfurt, Siesmayerstraße 61, 60323 Frankfurt, E-Mail: dominik.heukemes@stadt-frankfurt.de

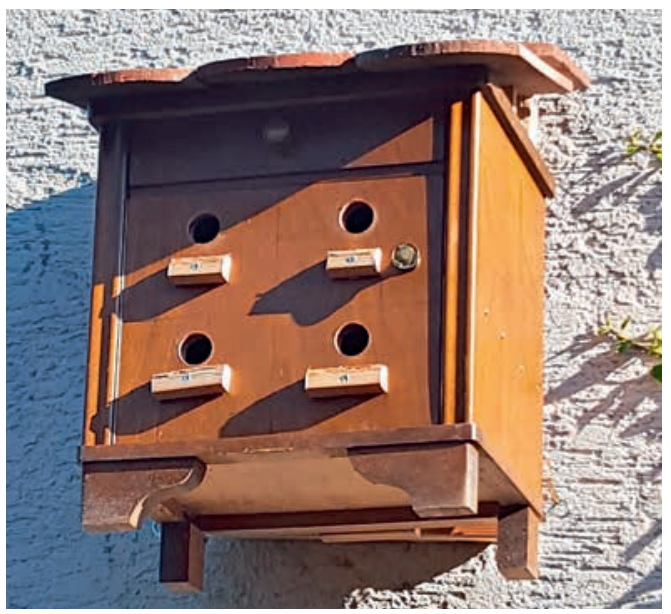

Abb. 7: An der Wand angebracht erwartet die Spatzenvilla in der kommenden Saison den ersten Bezug durch Spatzen. (Foto: D. Heukemes) 